\title{
Obrigatoriedade da Licença para Funcionamento em Salóes de Beleza no Distrito Federal
}

\author{
MANDATORY LICENSE FOR BEAUTY PARLOUR \\ IN DISTRITO FEDERAL
}

Maria das Graças Machado Britto(*)

\section{RESUMO}

Os ideais de beleza sempre permearam a existência humana. A prática do culto ao corpo e à estética é uma realidade em nossos dias. $O$ número de salões de beleza cresceu no Distrito Federal, e as atividades desenvolvidas nesses estabelecimentos são importantes do ponto de vista sanitário. Assim, foi descrito o novo paradigma estabelecido pela legislação que inaugurou a obrigatoriedade da Licença para Funcionamento em Salões de Beleza, em face à realidade do Distrito Federal. O estudo analítico, foi fundamentado em revisão bibliográfica e análise legislativa. Houve destaque para a vinculação entre as ações de Vigilância Sanitária, o poder econômico, e a supremacia da lei, perpassando pela legalidade dos Atos da Administração Pública, como ordens de serviços, desvinculadas de sua finalidade precipua, e decretos execrados de coerência, clareza e legalidade. Foram identificados e analisados entraves que dificultam a aquisição da Licença para Funcionamento em Salões de Beleza no Distrito Federal, impedindo o seu funcionamento e gerando prejuizos aos trabalhadores dessa área, que são cerceados do direito fundamental ao trabalho. Medidas coercitivas decorrentes do controle puramente cartorial, com edição e aplicação de atos administrativos questionáveis legalmente, não contemplam a prevenção de riscos e agravos à saúde nesses locais. É fundamental a implementação de ações de educação em saúde e inspeções sanitárias sistemáticas e de rotina para a promoção e proteção da saúde de trabalhadores e usuários desses serviços.

(*) Psicóloga, Especialista em Saúde Coletiva pela Universidade de Brasilia, Especialista em Direito Sanitário pela Fundação Oswaldo Cruz, Inspetora de Atividades Urbanas - VISA/DF. E-mail: mgbritto@uol.com.br. Recebido: 12.5.04, Aprovado: 23.8.04. 


\section{Descritores}

Vigilância sanitária; Salão de Beleza; Risco; Legislação.

\section{ABSTRACT}

The beauty standards always interpose the human existence. Actually, the esthetic and body veneration is a fact. The number of beauty parlours has increased in Distrito Federal and the activities performed on these shops are important at the sanitary point of view. As a mater of fact, it has been described the new rulers by the Law that established the need to have a special license for beauty parlours in District Federal. The analytic research has been based on a bibliographic revision and legislative analysis. It has been emphasized the need to tie up the actions between the Health Department, the economy agents and the power of law, including the decisions of the public administrations, like services permissions, not related with their purposes, and regulations issued without coherency, clearance and legality. It has been identified and analyzed some troubles that make difficult to obtain the license to open a beauty parlours shop in Distrito Federal, obstructing its operation and generating losses to this segment workers that are being restricted to their work fundamental rights. Compulsory measures due to simple notary records control do not consider the health risks and prevention in these places. It is important implementation of actions to establish health education and regular sanitary inspections to promote and protect the workers health and customers of this service.

\section{Key words}

Sanitary surveillance; Beuaty Parlour; Risk; Legislation.

\section{INTRODUÇÃO}

O culto à beleza é um aspecto característico da existência humana. Em nossos dias, a valorização do corpo e da estética, são fatores que interferem na inserção social. Afinal, a associação dos atributos físicos aos cognitivos, faz a diferença numa empreitada competitiva de qualquer natureza.

O Distrito Federal destaca-se de outras cidades quanto aos aspectos econômicos. É uma cidade com economia essencialmente terciária. É comum observar nas Quadras Comerciais das Asas Sul e Norte, estabelecimentos como Salões de Beleza, em grande número. São quase cinco 
mil estabelecimentos funcionando no Distrito Federal, administrados por pessoas advindas de vários segmentos da sociedade, que empreenderam, investiram e estabeleceram-se, buscando melhores condições de vida.

O Sindicato dos Salões de Barbeiros, Cabeleireiros, Profissionais Autônomos na Área de Beleza e Institutos de Beleza para Homens e Senhoras do DF (SINCAAB) mantém cadastrados 2.273 (dois mil, duzentos e setenta e três) salões de beleza no Distrito Federal (informação verbal)(1). Portanto, a descrição do novo paradigma que inaugurou a obrigatoriedade da Licença para Funcionamento em Salões de Beleza no Distrito Federal tornou-se importante, para demonstrar como interesses comerciais, puramente burocráticos e desvinculados dos principios que norteiam a Administração Pública, dificultam o acesso dos trabalhadores atuantes nesses locais, a direitos fundamentais garantidos na Constituição Federal:

\section{Constituição da República Federativa do Brasil, 1988}

Art. 5 Todos são iguais perante a lei, sem distinção de qualquer natureza, garantindo-se aos brasileiros e aos estrangeiros residentes no Pais a inviolabilidade do direito à vida, à liberdade, à igualdade, à segurança e à propriedade, nos termos seguintes:

II - ninguém será obrigado a fazer ou deixar de fazer alguma coisa senão em virtude da lei;

XIII - é livre o exercício de qualquer trabalho, oficcio ou profissão, atendidas as qualificações profissionais que a lei estabelecer. ${ }^{(2)}$

\section{DOS SALÕES DE BELEZA}

Os estabelecimentos prestadores de serviços de embelezamento, fazem parte de um setor econômico que cresce em número e em dimensão tecnológica, na medida em que a sociedade de consumo lança no mercado produtos cosméticos, cuja finalidade é enaltecer e realçar os traços físicos do cliente. De acordo com a tabela de classificação brasileira de ocupações (CBO), do Ministério do Trabalho, as pessoas que atuam em salões de beleza recebem títulos e códigos conforme a atividade exercida: $5161-05$ barbeiro; 5161 - 10 cabeleireiro (ajudante de cabeleireiro, auxiliar de cabeleireiro, cabeleireiro escovista, cabeleireiro feminino, cabeleireiro masculino, cabeleireiro penteador, cabeleireiro tinturista, cabeleireiro unissex); 5161 - 20 manicure ou manicuro; 5161 - 25 maquiador social ou maquilador; $5161-40$ pedicure (calista, pedicuro) ${ }^{(3)}$.

(1) DIAS, Raimundo. Entrevista concedida pelo Presidente do Sindicato dos Salóes de Barbeiros, Cabeleireiros, Profissionais Autônomos na Área de Beleza e Instituto de Beleza para Homens e Senhoras do Distrito Federal. Brasilia, 6 de outubro de 2003.

(2) BRASIL. Constituiçăo da República Federativa do Brasil: promulgada em 5 de outubro de 1988, 31. ed., Săo Paulo: Editora Saraiva, 2003.

(3) BRASIL. Ministério do Trabalho. Classificação brasileira de ocupaçðes - CBO 2002. Disponivel em: <www.mtecbo.gov.br/busca/descriçao.asp?codigo=5161>. Acesso em: 23.out. 2003. 
As condições gerais de exercício do trabalho nessas ocupações requerem profissionais polivalentes, capazes de executar diversas tarefas, trabalh ando em equipe, em horários irregulares, em posições desconfortáveis e expostos a longas jornadas de trabalho. As atividades são executadas pelos trabalhadores sem supervisão, exceto quando trabalham em grandes redes de institutos de beleza. Para a atuação de barbeiro, cabeleireiro, manicuro, pedicuro e maquiador, a tabela de classificação brasileira de ocupações (CBO) do Ministério do Trabalho, propõe no minimo, o ensino fundamental incompleto, curso de qualificação e até um ano de experiência profissional(4) $\mathbf{e}^{(5)}$.

\section{DOS RISCOS E AGRAVOS À SAÚDE}

Haja vista o desenvolvimento de técnicas cada vez mais sofisticadas e especificas no processo de embelezamento, os salões de beleza podem contribuir significativamente no processo saúde-doença da população. Qualquer técnica realizada sem a observância dos procedimentos adequados para o uso de produtos cosméticos ou instrumentos de trabaIho, pode gerar danos à aparência e/ou à saúde do cliente. A informação e a comunicação entre o cliente e o trabalhador da área, são elementos fundamentais para a garantia da qualidade dos serviços, não excluindo a ação do Estado, que deve fazer-se presente através de ações em vigilância sanitária, atuantes e eficazes, minimizando e/ou evitando danos à saúde do usuário.

Pleitos para ações indenizatórias decorrentes de serviços mal prestados em salões de beleza já estão acontecendo nos Tribunais de Justiça. São pleitos viabilizados pela incidência no Código de Defesa do Consumidor, instrumento legal que tornou possivel ao consumidor e usuário estreitar uma relação de consumo mais simétrica, construindo par e par uma relação de respeito e dignidade(6).

Jurisprudência - TJ do Rio de Janeiro, 2003.

Décima Quinta Câmara Cível Tribunal de Justiça do Estado do Rio de Janeiro

(4) A classificação brasileira de ocupações - CBO 2002 do Ministério do Trabalho não codifica a atividade de depilação nem titula o trabalhador que se ocupa dessa área especificamente. Pela descrição de atividades das áreas referidas pela tabela, a depilação pode ser desenvolvida por qualquer um dos trabalhadores já menciònados. Observa-se, entretanto, a oferta no mercado de cursos especificos para essa atividade.

(5) BRASIL. CBO. Op. cit.

(6) BRASIL. Lei n. 8.078, de 11 de setembro de 1990. Dispõe sobre a proteção do consumidor e dá outras providências. 
Apelação Civel n. 28.960

Apelante: Hayr Life Boutique Ltda.

Apelada: Elaine Helena dos Santos

Relator: Des. Henrique Magalhães de Almeida.

Ementa: Ação indenizatória por fato de serviço mal prestado por cabeleireiro. Incidencia do CDC, uma vez demonstrados o nexo causal e o resultado danoso, com queda indesejada de cabelos. Indenização que se concede, improvendo-se o recurso.

\section{Acórdão}

Vistos, relatados e discutidos estes autos da Apelação Civel n. 2002.001.28960, em que é apelante Hayr Life Boutique Ltda., sendo apelada Elaine Helena dos Santos. Acordam os Desembargadores da $15^{\mathrm{a}}$ Câmara Cível do Tribunal de Justiça do Estado do Rio de Janeiro, por unanimidade, em negar provimento de recurso, nos termos do voto do Relator. ${ }^{(7)}$

O grau de complexidade das técnicas realizadas em um processo de embelezamento em nivel de um salão de beleza, embora seja considerado baixo, essas técnicas podem acarretar riscos ou agravos à saúde, de clientes e funcionários desses serviços. São práticas que envolvem o contato entre o cliente e o profissional, e ainda, o compartilhamento de equipamentos, instrumentos, ambientes e superficies.

Conforme relatado no estudo de Johnson e outros, realizado em North York (Canadá), em agosto de 1996, envolvendo 120 (cento e vinte) estabelecimentos que realizavam serviços de manicuro e pedicuro na área urbana de Ontário, em 72 (setenta e dois) dos estabelecimentos envolvidos, $60 \%$ (sessenta por cento), representavam risco para transmissão de infecções e $40 \%$ (quarenta por cento) dos profissionais referiam estar imunizados contra a hepatite $B$. Os profissionais referiam ainda, reutilizar quase sempre os seus instrumentos de trabalho e era comum o uso de álcool isopropilico como desinfetante. Não era prática comum a utilização de luvas durante suas atividades e alegaram não seguir as precauções universais quando ocorriam acidentes de corte envolvendo a clientes ou a eles mesmos ${ }^{(8)}$ (tradução nossa).

(7) RIO DE JANEIRO. Tribunal de Justiça do Estado do Rio de Janeiro. Apelação Civel $n$. 2002.001.28960. Disponivel em: <www.tj.rj.gov.br/consulta/frameconsulta_wi.htm>. Acesso em: 23 out. 2003.

Ementa: Ação indenizatória por fato de serviço mal prestado por cabeleireiro. Incidência do $C D C$, uma vez que demonstrados o nexo causal e o resultado danoso, com queda indesejada dos cabelos. Indenização que concede, improvendo-se o recurso. Acórdão: Negar provimento ao recurso, nos termos do voto do Relator. Des. Henrique Magalhães de Almeida. Registrado em 27.3.03.

(8) JOHNSON, I et alii. Survey of infection control procedures at manicure and pedicure establishments in North York. In: Canadian Journal of Public Health, Canadá, v. 92, n. 2, p. 134$137,2001$. 
No Brasil, de acordo com Gir e Gessolo, a situação não é diferente. Entrevista realizada com quarenta manicuras na cidade de Ribeirão Preto, com a finalidade de avaliar seus conhecimentos acerca de aspectos gerais sobre AIDS e as alterações ocorridas nas suas ações profissionais com o advento desta sindrome, revelou que os meios de esterilização utilizados por $100 \%$ (cem por cento) delas não eram eficazes para a inativação do $\operatorname{HIV}^{(9)}$.

\section{DA LEGISLAÇÃO UTILIZADA NO DISTRITO FEDERAL}

Levando-se em conta a vinculação da ordem da saúde pública com as atividades desenvolvidas em um salão de beleza, faz-se necessário estabelecer a correlação desta vinculação com o conjunto de normas jurídicas e administrativas, que compõem e embasam as ações de vigilância sanitária nesses serviços. Assim é o entendimento de Costa:

Dada a natureza das ações - predominantemente voltadas à regulação do poder econômico para garantir os interesses sanitários da coletividade - as práticas da Visa, além do conhecimento técnico-científico atualizado, devem pautar-se pelos principios e regras juridicas e pelo conjunto de leis fixadas no ordenamento juridico; isto para não haver exorbitância do poder de autoridade e serem respeitados os direitos individuais e os direitos coletivos que também estão assentados na ordem juridica do pais. ${ }^{(10)}$

No Distrito Federal, as questões pertinentes ao funcionamento de salões de beleza estão contempladas no Livro II, Titulo IV, Capitulo VII, Seção II do Regulamento Aprovado pelo Decreto n. 8.386/ 85 (Código Sanitário do DF), que trata dos Institutos e Salões de Beleza, sem responsabilidade de profissionais de saúde, cabeleireiros, barbearias e casas de banho.

\section{REGULAMENTO APROVADO PELO DECRETO N. 8.386/85}

Art. 81. Os locais em que se instalarem Institutos e/ou Salões de Beleza, sem responsabilidade de profissional de saúde, Cabeleireiros e Barbearias, terão:

(9) GIR, E.; GESSOLO, F. Conhecimentos sobre AIDS e alterações nas ações profissionais das manicuras de Ribeirão Preto. Revista da Escola de Enfermagem - USP. São Paulo, v. 32, n. 2 , p. $91-100,1998$.

(10) COSTA, Edná Alves. Vigiláncia sanitária, saúde e cidadania, p. 17. In: CAMPOS, F. Eduardo et al. (Org.). Cadernos de Saúde Pública. Belo Horizonte: Ed. Coopmed, 2001, v. 4, p. 13-27. 
I - área minima de $8 \mathrm{~m}^{2}$ e mais de $4 \mathrm{~m}^{2}$ por cadeira instalada excedente a duas;

II - piso revestido de material liso, impermeável e resistente;

III - paredes revestidas, até a altura do teto de material liso, impermeável, resistente, em cores claras.

$\S 1^{\circ}$ Todo o estabelecimento destinado a instituto ou salão de beleza, cabeleireiro, barbearia e casas de banho, deverá ser abastecido de água potável canalizada e possuir, no mínimo, um vaso sanitário e um lavatório.

$\S 2^{\circ}$ Nos recintos destinados aos estabelecimentos referidos neste artigo serão permitidos outros ramos de atividade comercial afins, a critério da autoridade sanitária.

$\S 5^{\circ} \mathrm{em}$ todos os estabelecimentos referidos nesta Seção é obrigatória a desinfecção de locais, equipamentos e utensilios ${ }^{(11)}$.

Convém lembrar, que o Código Sanitário do DF foi publicado em 1985 e impõe obrigações relativas a procedimentos, bem como à área e estrutura física dos estabelecimentos referidos; contudo, não cria obrigatoriedade de responsabilidade técnica para estes locais, nem estabelece a necessidade de posse da Licença para Funcionamento. A obrigação de posse do referido documento foi criada a partir de 1993, quando da regulamentação da Lei n. 509/93, pelo Decreto n. 15.270 do mesmo ano. A Lei, que fora aprovada pela Câmara Legislativa do DF, não criara obrigação para aquisição da Licença para Funcionamento em Salões de Beleza, nem condicionara seu funcionamento à responsabilidade técnica de um profissional, haja vista, a ausência de regulamentação de profissão nessa área. Trata apenas da obrigatoriedade da utilização de material descartável ou esterilização de artigos, no exercicio das atividades nesses locais.

Lein. 509/93

Art. $1^{\circ}$ Os profissionais acupunturistas, cabeleireiros, calistas, barbeiros, manicuros e outros afins ficam obrigados a utilizar material descartável ou esterilizável no exercicio de suas atividades.

Parágrafo único. O material descartável ou equipamento para esterilização de que trata este artigo será fornecido pelo estabelecimento comercial a seus empregados, quando for o caso. ${ }^{(12)}$

(11) DISTRITO FEDERAL. Decreto n. 8.386, de 9 de janeiro de 1985. Aprova o Regulamento da promoção, proteção e recuperação da saúde no Distrito Federal

(12) DISTRITO FEDERAL. Lei $n$. 509, de 22 de julho de 1993. Dispõe sobre a obrigatoriedade de utilização de material descartável ou esterilizável por profissionais acupunturistas, cabeleireiros, calistas, barbeiros, manicures e outros. 
O Decreto n. 15.270/93, entretanto, ao regulamentar a referida lei, inova o seu teor, criando a obrigação da posse da Licença para Funcionamento nos estabelecimentos por ele tratados, restringindo, portanto, direitos dos trabalhadores atuantes nesses locais.

Decreto n. $15.270 / 93$

Art. $3^{\circ}$ Os estabelecimentos e profissionais legalmente instalados que na data da vigência deste Decreto que exerçam uma ou mais atividades de que trata o art. 19, deverão solicitar sua inscriçăo no "Cadastro Sanitário", bem como requerer seu licenciamento junto ao Departamento de Fiscalização de Saúde da Secretaria de Saúde do Distrito Federal, no prazo máximo de 30 (trinta) dias a contar da publicaçăo deste Decreto.

Parágrafo único. A Licença para Funcionamento é válida por um periodo de 12 (doze) meses, devendo ser renovada anualmente, até 10 de junho do exercicio subseqüente. ${ }^{(13)}$

Segundo Caetano, a lei formal é unicamente sujeita à Constituição, assim pode ser inovadora, criando ou restringindo direitos na Ordem Juridica. Já o regulamento precisa respeitar as leis, não pode conter preceitos que contrariem disposições constantes de leis formais. Concluindo, portanto, que a ilegalidade dos preceitos regulamentares constitui um vicio que afeta a sua validade ${ }^{(14)}$.

No Distrito Federal, o periodo entre 1999 e 2003, foi marcado pela elaboração de normas que vincularam as atividades de Vigilância Sanitária às atividades tributárias. A Lei das Taxas como é denominada a Lei Complementar n. 264/99, refere os fatores geradores das taxas a serem cobradas, bem como, sobre o contribuinte ou responsável, cálculo e pagamento dessas taxas.

\section{Lei Complementarn. 264/99}

Art. 15. A Taxa de Vigilåncia Sanitária tem como fator gerador a inspeção dos locais onde se fabricam, produzem, transformam, preparam, manipulam, purificam, fracionam, embalam ou reembalam, importam, exportam, armazenam, distribuem, expedem, transportam, vendem e compram alimentos, produtos alimenticios, medicamentos, drogas, insumos farmacêuticos, produtos de higiene, cosméticos, correlatos, embalagens, saneantes, utensilios e aparelhos que interessem à saúde e de todos os estabelecimentos direta e indiretamente ligados à saúde.

Art. 16. Contribuinte da taxa é toda pessoa fisica ou jurídica que exerça qualquer das atividades descritas no artigo anterior. ${ }^{(15)}$

(13) DISTRITO FEDERAL. Decreto $n$. 15.270, de 2 de dezembro de 1993. Regulamenta o funcionamento de barbearias, salōes de beleza, clinicas acupunturistas e outros afins.

(14) CAETANO, Marcello. Principios fundamentais do direito administrativo. Coimbra: Livraria Medina, 1996. p. 80 e 84.

(15) DISTRITO FEDERAL. Lei n. 264, de 14 de dezembro de 1999. Dá nova redação ao art. $4^{9}$ da Lei Complementar n. 4, de 30 de dezembro de 1994. 
Não é possivel falar em inconstitucionalidade para a Lei das Taxas, considerando o disposto no art. 145 da Constituição brasileira, in verbis:

Constituição da República Federativa do Brasil, 1988

Art. 145. A União, os Estados, o Distrito Federal e os Municipios poderão instituir os seguintes tributos:

II - taxas, em razão do exercício do poder de polícia ou pela utilização, efetiva ou potencial, de serviços públicos específicos e divisiveis, prestados ao contribuinte ou postos a sua disposição;

§ 2ำ As taxas não poderão ter base de cálculo própria de impostos. ${ }^{(16)}$

As taxas de vigilância sanitária cobradas no Distrito Federal, contudo, não foram criadas levando-se em consideração a capacidade econômica do contribuinte, nem respeitando-se os principios da razoabilidade e proporcionalidade. Os valores cobrados não foram calculados modicamente, de modo que fosse viabilizado o processo arrecadatório, ao contrário, dificultam a arrecadação devido à incompatibilidade com as atividades econômicas dos estabelecimentos, bem como à incoerência no momento da classificação quanto ao eventual risco pertinente a esses estabelecimentos.

Assim, o Decreto n. 22.438/01 regulamentou o capítulo IV da Lei Complementar n. 264/99, dispondo sobre a taxa de Vigilância Sanitária, fator gerador, contribuinte, lançamento, pagamento e disposições.

Decreto n. 22.438/01

Art. $7^{\circ}$ Para efeito da aplicação das medidas constantes neste Decreto serão adotadas as seguintes definições:

I-Alto Risco - é aquela atividade em que o usuário dos serviços, o consumidor de produtos ou o trabalhador está exposto a procedimentos que podem gerar agravos ou afetar a saúde em grau elevado, em qualquer de suas etapas, sendo necessária pelo menos uma inspeção técnica por ano.

II - Médio Risco - é aquela atividade em que o usuário dos serviços, o consumidor de produtos ou o trabalhador está exposto a procedimentos que podem gerar agravos ou afetar a saúde a médio e longo prazo, em qualquer de suas etapas, sendo necessária pelo menos uma inspeção técnica por ano.

III - Baixo Risco - é aquela atividade que pode gerar um mínimo de agravo a saúde, com ocorrência a longo prazo, ao usuário dos serviços, consumidor de produtos ou trabalhador, sendo necessária uma inspeção técnica por ano.(17),(18)

(16) BRASIL. Constituiçăo da República Federativa do Brasil. loc. cit.

(17) DISTRITO FEDERAL. Decreto $n .22 .438$, de 2 de outubro de 2001. Regulamenta o capitulo IV da Lei Complementar n. 264/99.

(18) A classificação quanto ao risco é diferenciada; porém, é estabelecido igual número minimo de inspeções anuais. 
Dois anos mais tarde, o Decreto n. $24.043 / 03$ estipulou nova redação para os arts. $4^{\circ}, 5^{\circ}, 7^{\circ}$, inciso IX, $9^{\circ}, 11,15$ e o anexo único do Decreto $\mathrm{n}$. 22.438/01. Visando ponderar os excessos do decreto anterior, alterou as Tabelas de Classificação de Riscos das Atividades. Os salões de beleza que dispunham de manicuro, pedicuro e depilação e que, anteriormente foram classificados como Alto Risco, igualados aos estabelecimentos hospitalares, passaram então a ser classificados como de Médio Risco e codificados como Serviços Pessoais. Aqueles salões de beleza que somente ofereciam os serviços de cabeleireiros, passaram a constituir a Tabela de Baixo Risco, e foram também codificados como Serviço Pessoal(19).

Se a taxa de vigilância sanitária, possui como valor gerador o exercicio do poder de polícia prestado efetivamente à população, ou colocado à sua disposição, então porque não estabelecer a definição das atividades desenvolvidas pelos serviços, utilizando-se os critérios preconizados pela Norma Operacional Básica (NOB) de 1996, que vincula o repasse para a Vigilância Sanitária, levando-se em conta a complexidade das ações? (alta, média e baixa)(20). Seria mais coerente, pois existe a dificuldade em quantificar o risco(21) de uma atividade desenvolvida em um estabelecimento previamente. Além do que, um estabelecimento pode demandar maior tempo em uma inspeção, devido a sua alta complexidade e ao mesmo tempo, não oferecer um risco tão alto. Então, se o Estado cobra o serviço de inspeção oferecido, porque não cobrar pela complexidade desses serviços?

Ignorando-se ainda, os principios da razoabilidade, proporcionalidade, legalidade, e aplicando-se erroneamente o poder discricionário da administração pública, no que se aplica aos salões de beleza no DF, foram criados e editados outros atos administrativos, com o intuito de fazer valer a Lei das Taxas.

O Decreto n. 22.704, de 22 de janeiro de 2002, dispõe sobre a alteração do art. 77 do Decreto n. 8.386, de 9 de janeiro de $1985^{(22)}$. Foi publicado visando unicamente o fortalecimento do escopo normativo da administração pública, na imposição da obrigatoriedade da Licença para Funcionamento e necessidade de responsabilidade técnica em salões de beleza e outros estabelecimentos. Entretanto, existe um vicio na formalização do ato, sua ementa carece de perfeição formal na estrutura textual, já que o

(19) DISTRITO FEDERAL. Decreto $n$. 24.043, de 12 de setembro de 2003. Dá nova redação para os arts. $4^{9}, 5^{9}, 7^{9}$ inciso IX, 99, 11, 15 e 0 anexo único do Decreto $n$. 22.438/01.

(20) BRASIL. Ministério da Saúde. Norma operacional básica do Sistema Único de Saúde SUS. Brasilia: Diário Oficial da República Federativa do Brasil, 1997.

(21) Veja-se como abordagem de risco o estudo de GUILAM, M. C. Rodrigues; CASTIEL, Luis David. Risco e Saúde, p.1-2. In: GUILAM, M. C. Rodrigues. O conceito de risco: sua utilizaçăo pela epidemiologia, engenharia e ciências sociais.1996. Dissertação (Mestrado) - Universidade Estadual do Rio de Janeiro, 1996.

(22) DISTRITO FEDERAL. Decreto n. 22.704, de 22 de janeiro de 2002. Dispõe sobre a alteração do art. 77 do Decreto n. 8.386, de 9 de janeiro de 1985 . 
art. 77 referido, faz parte do corpo de disposições do Regulamento aprovado pelo Decreto n. 8.386/85, que na verdade, possui apenas dois artigos. Ressalta-se ainda, que o Decreto n. 22.704/02 é autônomo, não encontra amparo na Constituição Federal. Cria obrigações, restringe direitos, ignorando o teor de normas especificas.

É fato, que à administração pública é vedado formular exigências por meio de atos administrativos, que extrapolem os termos de normas hierarquicamente superiores. Contudo, entre fevereiro e setembro de 2002, foram expedidas três ordens de serviço, pela Diretoria de Vigilância Sanitária do Distrito Federal, na tentativa de viabilizar a eficácia do Decreto n. 22.704/ 02, já que este não faz distinção entre os estabelecimentos vinculados a conselhos de classe, obrigando a posse da Licença para Funcionamento também para aqueles que não desenvolvem atividades relacionadas diretamente à Saúde.

Gasparini ressalta, que as ordens de serviços são fórmulas com as quais os superiores transmitem, aos respectivos subordinados, a maneira de ser conduzido certo e determinado serviço, no que respeita aos aspectos administrativos e técnicos. Uma ordem de serviço não pode criar obrigações aos administrados, senão em virtude da Lei(23).

A Ordem de Serviço n. 2/02 foi emitida para disciplinar os requisitos de qualificação técnica e profissional na admissão de responsável técnico para os estabelecimentos elencados pelo Decreto n. 22.704/02. Conforme a ordem de serviço, os salões de beleza, cabeleireiros e barbearias deveriam manter responsável técnico diplomado por empresas públicas (SESC, SENAI, SENAC, SEBRAE e outros) e/ou empresas privadas que fossem credenciadas junto ao Ministério de Educação e/ou do Trabalho, ou por qualquer outro órgão público com a devida comprovação(24). Com a vigência da ordem de serviço tornou-se praticamente impossivel aos administrados a posse da Licença para Funcionamento, mesmo após recolher a taxa de $R \$ 96,54$ através do DAR (documento de arrecadação) à época, atualmente o valor da taxa para aquisição do documento é de $R \$ 106,62$.

No que se refere a Salões de Beleza, a Ordem de Serviço n. 013/02, alterou a Ordem de Serviço n. 002/02 quanto aos requisitos exigidos quando da apresentação do diploma ou certificado no Núcleo de Inspeção. Esses documentos agora precisavam ser emitidos por instituições educacionais credenciadas junto à Secretaria de Educação do Distrito Federal, com a devida comprovação(25). A Ordem de Serviço citava como a anterior, as

(23) GASPARINI, Diogenes. Direito administrativo. 5. ed., São Paulo: Saraiva, 2000. p. 82.

(24) DISTRITO FEDERAL. Diretoria de Vigilância Sanitária. Ordem de Serviço n. 2, de 26 de fevereiro de 2002. Disciplina os requisitos de qualificação técnica e profissional na admissão de responsável técnico para os estabelecimentos que menciona.

(25) DISTRITO FEDERAL. Diretoria de Vigilância Sanitária. Ordem de Serviço n. 13, de 23 de julho de 2002. Altera a Ordem de Serviço n. 2, de 26 de fevereiro de 2002, que disciplina os requisitos de qualificaçăo técnica e profissional na admissão de responsável técnico para os estabelecimentos que menciona. 
instituições que atendiam a esse critério. Continuaram ocorrendo os casos de cabeleireiros, manicuros, pedicuros, barbeiros e depiladores, que após vinte ou trinta anos de trabalho na área, tiveram de submeter-se a testes práticos de conhecimentos nas instituições referidas, tendo que arcar com os custos financeiros para a obtenção do certificado exigido pela Vigilância Sanitária do Distrito Federal.

É fato que a Secretaria de Educação através da Resolução n. 1/03, estabelece normas para o Sistema de Ensino do Distrito Federal, em observância às disposições da Lei n. 9.394, de 20 de dezembro de 1996 Diretrizes e Bases da Educação Nacional ${ }^{(26)}$, propondo a resolução, a livre oferta dos cursos profissionalizantes.

\section{Resolução n. 01/03}

Art.44. A educação profissional compreende os seguintes niveis:

I - básico - educação profissional não-formal, não sujeita à regulamentação curricular, destinada a qualificar e profissionalizar trabalhadores, independente de escolaridade prévia;

Art.46. Os cursos de educação profissional de nivel básico, de atualização e aperfeiçoamento, năo sujeitos à regulamentação curricular, são de livre oferta das instituições responsáveis pela respectiva certificação.

Parágrafo único. A livre oferta de cursos referidos no caput para atender demandas do exercício profissional năo requer autorização da secretaria de Estado de Educação. ${ }^{(27)}$

Levando-se em conta todos os entraves gerados, a Diretoria de Vigilância Sanitária do Distrito Federal, emitiu a Ordem de Serviço n. 11/03, atualmente em vigor. O responsável técnico por salões de beleza com cabeleireiro, barbearia, manicuro, pedicuro e depilação deve apresentar a diplomação técnica em instituição credenciada ou certificação em cursos livres com personalidade juridica própria (CNPJ), referindo ainda a necessidade de apresentação do programa de formação (matérias e carga horária) para as atividades ${ }^{(28)}$. Entretanto; o abrandamento da Ordem de Serviço não excluiu a obrigação de posse da Licença para Funcionamento.

Considerando-se os escritos de Guimarães, as ordens de serviços mencionadas apresentam problemas relacionados à estrutura textual típica dos atos normativos. As ementas referenciais, como as que alteram

(26) BRASIL. Lei n. 9.394, de 20 de dezembro de 1996. Estabelece as diretrizes e bases da educação nacional.

(27) DISTRITO FEDERAL. Conselho de Educaçăo. Resoluçăo n. 1, de 26 de agosto de 2003. Estabelece normas para o sistema de ensino do Distrito Federal.

(28) DISTRITO FEDERAL. Diretoria de Vigilåncia Sanitária. Ordem de Serviço $n$. 11 , de $1^{9}$ de setembro de 2003. Altera a Ordem de Serviço n. 2, de 26 de fevereiro de 2002, que disciplina os requisitos de qualificação técnica e profissional na admissão de responsável ténico para as atividades e/ou que menciona e dá outras providências. 
algum dispositivo, exigem que o dispositivo anterior seja indexado no novo ato para a leitura imediata do mesmo. Isso não acontece nas Ordens de Serviço n. 13/02 e 11/03, que não possuem tal estruturação(29).

Descabida a exigência de responsabilidade técnica para estabelecimentos que carecem de ocupações regulamentadas, segmento que forma um importante contingente de força de trabalho no Distrito Federal, os trabalhadores de atividades em Salões de Beleza são demandantes de regulamentação do exercicio de suas atividades, sem, contudo, obterem sucesso.

\section{CONCLUSÃO}

Após as considerações realizadas, torna-se relevante a reflexão sobre a importância da Licença para Funcionamento no bojo das ações de saúde pública, em estabelecimentos onde os trabalhadores ainda não possuem regulamentação para o seu ofício. Responsabilidade Técnica implica regulamentação, definição de critérios para o exercício da profissão; implica a criação de Conselhos de Classe; sistematização do saber.

Cabe questionar se a finalidade precipua das ações de Vigilância Sanitária em Salões de Beleza, no Distrito Federal, resguardando a saúde dos usuários desses serviços, bem como a saúde dos próprios trabalhadores desse setor, estaria sendo levada a termo, com medidas coercitivas decorrentes do controle puramente cartorial, como a obrigação de posse de Licença para Funcionamento, com a edição e aplicação de atos questionáveis do ponto de vista legal.

O monitoramento dos serviços desenvolvidos em Salões de Beleza, estaria melhor embasado com a missão da Vigilância Sanitária, se realizado através de ações de educação em saúde e inspeções sistemáticas e de rotina, com a atuação transdisciplinar entre os técnicos de Vigilância Sanitária, os trabalhadores envolvidos no processo e a comunidade usuária dos serviços de embelezamento.

\section{REFERÊNCIAS BIBLIOGRÁFICAS}

BRASIL. Constituição da República Federativa do Brasil: promulgada em 5 de outubro de 1988, 31. ed., São Paulo: Editora Saraiva, 2003.

proteção do consumidor e dá outras providências.

(29) GUIMARÃES, José A. Chaves. Elementos de técnica legislativa como subsidio à análise de Atos Normativos. Marilia - SP: Unesp, 2002, p. 1-2; 6. 
Lei n. 9.394, de 20 de dezembro de 1996. Estabelece as diretrizes e bases da educação nacional.

Ministério do Trabalho. Classificação brasileira de ocupações - CBO 2002. Disponivel em www.mtecbo.gov.br/busca/descriçao.asp? codigo $=5161$. Acesso em: 23.10.03.

Ministério da Saúde. Norma operacional básica do Sistema Único de Saúde - SUS. Brasilia: Diário Oficial da República Federativa do Brasil, 1997.

CAETANO, Marcello. Principios fundamentais do direito administrativo. Coimbra: Livraria Medina, 1996.

COSTA, E. A.; ROZENFELD, S. Constituição da Vigilância Sanitária no Brasil, p. 17. In: ROZENFELD, S. (org.) Fundamentos da Vigilância Sanitária. Rio de Janeiro: Editora FIOCRUZ, 2001.

DIAS, Raimundo. Presidente do Sindicato dos Salões de Barbeiros, Cabeleireiros, Profissionais Autônomos na Área de Beleza e Instituto de Beleza para Homens e Senhoras do Distrito Federal. Depoimento (out. 2003). Entrevistadora: Maria das Graças M. Britto. Brasília; 2003.

DISTRITO FEDERAL. Decreto n. 8.386, de 9 de janeiro de 1985. Aprova o Regulamento da promoção, proteção e recuperação da saúde no Distrito Federal.

Decreto $n$. 15.270, de 2 de dezembro de 1993. Regulamenta o funcionamento de barbearias, salões de beleza, clínicas acupunturistas e outros afins.

Decreto $n$. 22.438, de 2 de outubro de 2001. Regulamenta o capitulo IV da Lei Complementar n. 264 de 14 de dezembro de 1999, que dispõe sobre as Taxas de Vigilância Sanitária do Distrito Federal, e dá outras providências.

Decreto $n$. 24.043, de 12 de setembro de 2003. Dá nova redação para os arts. $4^{\circ}, 5^{\circ}, 7^{\circ}$ inciso $\mathrm{IX}, 9^{\circ}, 11,15$ e 0 anexo único do Decreto n. 22.438/01.

Decreto n. 22.704, de 22 de janeiro de 2002. Dispõe sobre a alteração do art. 77 do Decreto n. 8.386 (Regulamento), de 9 de janeiro de 1985.

. Lei $n$. 509, de 22 de julho de 1993. Dispõe sobre a obrigatoriedade de utilização de material descartável ou esterilizável por profissionais acupunturistas, cabeleireiros, calistas, barbeiros, manicures e outros.

. Lei $n$. 264, de 14 de dezembro de 1999. Dá nova redação ao art. $4^{\circ}$ da Lei Complementar n. 4, de 30 de dezembro de 1994.

GASPARINI, Diogenes. Direito administrativo. 5. ed., São Paulo: Saraiva, 2000. 
GIR, E.; GESSOLO, F. Conhecimentos sobre AIDS e alterações nas ações profissionais das manicuras de Ribeirão Preto. Revista da Escola de Enfermagem - USP. São Paulo: v. 32, n. 2, 1998.

GUIMARÃES, José A. Chaves. Elementos de Técnicas Legislativas como Subsidio à Análise de Atos Normativos. Marília - SP: UNESP, 2002.

JOHNSON, 1 et alii. Survey of infection control procedures at manicure and pedicure establishments in North. In: Canadian Journal of Public Health, v. 92, n. 2, Canadá. 2001.

RIO DE JANEIRO. Tribunal de Justiça do Estado do Rio de Janeiro. Apelação Civel n. 2002.001.28960. Disponivel em: www.tj.rj.gov.br/consulta/ frameconsulta_wi.htm. Acesso em: 23 out. 2003. 